\title{
CONSUMER PREFERENCE FOR ALTERNATIVE MILK PACKAGING: THE CASE OF AN INFERRED ENVIRONMENTAL ATTRIBUTE
}

\author{
CLINTON L. NEILL* \\ Department of Agricultural and Applied Economics, Texas Tech University, Lubbock, Texas \\ Department of Agricultural Economics, Oklahoma State University, Stillwater, Oklahoma \\ RYAN B. WILLIAMS \\ Department of Agricultural and Applied Economics, Texas Tech University, Lubbock, Texas
}

\begin{abstract}
Ecolabeling allows firms to segment a market by informing consumers about unobservable attributes of a product. Previous studies evaluate consumer preferences for products explicitly labeled as possessing positive environmental attributes. This research evaluates consumers' willingness to pay for a product that is perceived by the consumer as having environmentally friendly attributes. We explore glass packaging for fluid milk as a case study. Data were collected through a contingent valuation survey, and a bound-and-a-half logit model was employed. The estimated premium is 59.78 cents with a premium between $\$ 0.73$ and $\$ 0.92$ for consumers more likely to prefer the glass alternative.
\end{abstract}

Keywords. Contingent valuation, environmental attributes, fluid milk, glass packaging

JEL Classifications. Q51, Q13, D12

\section{Introduction}

Consumers are increasingly making purchases of products that possess ecolabels or are labeled as locally grown/produced. Ecolabels are a voluntary labeling system that identifies a good or service as having a reduced environmental impact relative to comparable goods and services. The growth of ecolabeling is closely tied to sales of local and organic foods, which, despite a small market share, increased sevenfold between 2008 and 2013 (Greene, 2016).

Ecolabels and locally grown labels provide a clear signal to consumers that the product should be considered as being more environmentally friendly-whether true or not-than the alternative. Consumers demonstrate willingness to pay (WTP) a premium for such products. Some goods and services attract consumers

We would like to thank Dr. Rodney B. Holcomb and three anonymous reviewers for their comments on the preparation of this manuscript.

*Corresponding author e-mail: clinton.neill@okstate.edu 
via an inferred attribute without the benefit of such explicit labeling. In such instances, the consumer perceives a product to be environmentally friendly, but there are no observable identifiers that distinguish the product as being environmentally friendly.

Previous studies (Bajari and Benkard, 2001; Toro-González et al., 2013) have discussed the idea of an unobservable or inferred product attribute. These studies define an unobservable product attribute as it relates to flavor quality. Although the previous literature discusses matters of quality, the current study proposes a differentiating product attribute that is not based on personal quality measurements, but rather on consumer inclinations toward environmental impacts.

At times, a producer of a product is also a consumer of intermediate products that are vital to the production process; thus, producers also have preferences regarding the characteristics of the products that they purchase. In their study, Gallardo and Wang (2013) address this issue of WTP for pesticides' environmental features and social desirability bias. The central concern of the study was to determine if producers were willing to pay for pesticides that decrease the probability of pesticide toxicity to natural enemies along with determining if there was social pressure on pesticide choice. Their study evaluates unobservable product attributes resulting from the potential environmental attributes that are not guaranteed and, therefore, only perceived on the part of the consumer-or in this case, the producer purchasing the pesticide.

More recent studies have focused on decomposing WTP into two parts. Lusk, Schroeder, and Tonsor (2014) examine the separation of WTP estimates into preferences and beliefs. What these researchers show are misinterpretations of WTP when both segments of the estimates are not distinguished. They argue that surveys need to combine both preference elicitation and belief elicitation in order to extract accurate WTP estimates.

Johannson-Stenman and Martinsson (2006) proposed a model in which utility, besides being a function of the good's characteristics, was a function of the individual's perceived concern relative to the average perceived concern of others. Both Lusk and Norwood (2009a, 2009b) and Norwood and Lusk (2011) found that indirect valuation had the potential to provide better predictions of field behavior if social concerns were the primary contributor to bias and could therefore provide potentially improved predictions of WTP and market shares.

This study attempts to combine WTP estimates for an inferred environmental attribute with consumer perceptions about the attribute. Milk packaged in glass bottles is an example of a product with an inferred environmental attribute. In the past, dairies and creameries would ship glass bottles of milk to consumers within a 100-mile radius, and evidence suggests that glass-bottled milk retains a sense of nostalgic, local milk production (Hollywood et al., 2013; Thistlethwaite, 2010). With advancements in the production of alternative materials for packaging and transportation, the plastic milk bottle was adopted. According to Zaleski (1963), the plastic bottle is a viable alternative to glass-bottled milk because it is cheaper 
on a per unit basis and does not have to be returned. Today, however, consumers seem to be more cognizant of their environmental impacts and view the glass bottle as a recyclable that can assist in reducing waste. In fact, some studies suggest glass milk bottles have a lower total-life carbon footprint (irrespective of true economic costs) relative to plastic containers because of their reusability (e.g., Ghenai, 2012).

Glass-bottled packaging demand for nonalcoholic beverages had approximately $10 \%$ of the market share in 2013 (Transparency Market Research, 2014). We are particularly interested in evaluating consumers' perceived attitudes toward glass-bottled milk and how they respond to varying price points associated with the product. Neill and Williams (2015) show that the returnable glass bottle for milk has the lowest external cost when it is reused 8 times, relative to plastic and paperboard. The external cost is offset, however, by the private cost, which requires the returnable glass bottle to be reused 12 times in order to have a lower social cost relative to the alternatives. Thus, consumers may perceive that the returnable glass bottle is the better social option, even though, realistically, it is not.

We estimate a decomposed consumer WTP similar to Lusk, Schroeder, and Tonsor (2014) for glass-bottled milk through the use of a consumer intercept, bound-and-a-half contingent valuation (CV) survey. $\mathrm{CV}$ is a nonmarketvaluation method that is used to value specific changes from the status quo. In the CV method (CVM), individuals are asked about the status quo versus some alternative state of the world, which in this case is unconventional packaging of milk; WTP is then elicited for the alternative. The use of the CVM is common in the literature related to ecolabeling, as it allows consumers to consider all alternatives simultaneously (Lourerio and Hine, 2002; Loureiro, McCluskey, and Mittelhammer, 2001). The hypothesis for this study is that consumers are willing to pay a higher premium if they perceive that a returnable glass bottle is more environmentally friendly than a plastic jug, ceteris paribus.

\section{Data}

In order to extract consumer WTP for a returnable glass milk bottle, a survey was conducted in Lubbock, Texas, at the Market Street Grocery Store \#553 (4425 19th Street). We were unsuccessful in gaining permission from additional Market Street Grocery Store locations or other grocers. Data collection was approved by the Texas Tech University Human Research Protection Program Institutional Review Board and Market Street. Participants were solicited on two separate occasions: Saturday, April 27, and Monday, May 19, 2014. In total, 245 surveys were collected, and 229 were used in the analysis after removing incomplete surveys. It is noted that this sample size is small both in aggregate number and in respondent scope. 
The survey elicited demographic information and included a set of questions to determine the level of a respondent's proenvironmental attitude. The boundand-a-half CV instrument used for this study was in the form of a dichotomous choice system. Consumers were solicited to take the survey as they entered the grocery store. If they agreed to participate in the survey, the consumers were first asked how often they consume milk. Those that did not consume milk were not included in the analysis, as to control for this area of bias. Next, the consumers were asked if they would be willing to pay a specific premium for the glassbottled milk. If they said yes, the amount of the premium in the next question was doubled; if they said no, they were simply asked if they would be willing to pay any premium amount.

Table 1 shows the summary of statistics for the demographic characteristics and perception variables collected from the consumers. The average responding consumer was between 30 and 45 years of age, with two or three people living in his or her household. The average annual household income of the consumers surveyed was approximately $\$ 56,650$. These average characteristics are similar to those reported in the latest U.S. Census for Lubbock, Texas (U.S. Census Bureau, 2014).

Other variables not in Table 1 but also included in the analysis were as follows: Perception (i.e., whether the consumer perceived the glass bottle to be more environmentally friendly as compared with plastic); Personal responsibility (i.e., whether the consumer thought that it was solely his or her responsibility to seek out environmentally friendly products); and Local (i.e., certain versions of the survey state that the milk in the glass bottle was produced locally).

\section{Methods}

In order to estimate WTP through CVM, an interval model was used as a function of the demographic variables and other characteristics of the individual. The probability that the WTP lies between a specific lower and upper bound was estimated through a log-likelihood function. The lower and upper bounds of WTP can be estimated using the Turnbull estimator; however, here we are more interested in a mean WTP.

The interval data model allows the efficient use of data to estimate WTP. The following econometric estimation is taken from Lopez-Feldman (2012). Let us define $y_{i}^{1}$ and $y_{i}^{2}$ as the dichotomous variables that capture the response to the first and second closed questions. The probability that an individual answers "yes" to the first question and "no" to the second can then be expressed as

$$
\operatorname{Pr}\left(y_{i}^{1}=1, y_{i}^{2}=0 \mid z_{i}\right)=\operatorname{Pr}(s, n),
$$

where $s$ and $n$ represents "yes" and "no," respectively. This notation is to simplify notation on the right-hand side of the expression without omitting the fact that the probability is conditional on the values of the explanatory variables. 
Table 1. Summary of Statistics for Survey Respondents

\begin{tabular}{|c|c|c|c|c|}
\hline Variable & Description & $\begin{array}{l}\text { Percentage of } \\
\text { Occurrence }\end{array}$ & Mean & $\begin{array}{l}\text { Standard } \\
\text { Deviation }\end{array}$ \\
\hline \multirow[t]{5}{*}{ Age } & Age of the consumer: & & 1.9039 & 1.0171 \\
\hline & $1=18-30$ & 47.60 & & \\
\hline & $2=30-45$ & 23.58 & & \\
\hline & $3=45-60$ & 19.65 & & \\
\hline & $4=$ Older than 60 & 9.17 & & \\
\hline \multirow{3}{*}{ Gender } & Dummy variable: & & 0.6245 & 0.4853 \\
\hline & $0=$ Male & 37.55 & & \\
\hline & $1=$ Female & 62.45 & & \\
\hline \multirow[t]{6}{*}{ Household size } & $\begin{array}{l}\text { Number of people currently living } \\
\text { in household: }\end{array}$ & & 2.5721 & 1.2911 \\
\hline & $1=1$ & 24.02 & & \\
\hline & $2=2$ & 30.57 & & \\
\hline & $3=3$ & 20.52 & & \\
\hline & $4=4$ & 13.97 & & \\
\hline & $5=$ More than 4 & 10.92 & & \\
\hline \multirow[t]{6}{*}{ Education } & $\begin{array}{l}\text { Highest level of education } \\
\text { completed: }\end{array}$ & & 2.6245 & 0.9265 \\
\hline & $0=$ Some school & 0.44 & & \\
\hline & $1=$ High school diploma & 9.61 & & \\
\hline & $2=$ Some college & 37.12 & & \\
\hline & $3=$ Bachelor's degree & 32.75 & & \\
\hline & $4=$ Advanced degree & 20.09 & & \\
\hline \multirow{7}{*}{$\begin{array}{l}\text { Household } \\
\text { income }\end{array}$} & Household's income level: & & $\$ 56,650$ & $\$ 36,870$ \\
\hline & Less than $\$ 20,000$ & 24.45 & & \\
\hline & $\$ 20,000-\$ 35,000$ & 8.73 & & \\
\hline & $\$ 35,001-\$ 50,000$ & 13.54 & & \\
\hline & $\$ 50,001-\$ 70,000$ & 18.34 & & \\
\hline & $\$ 70,001-\$ 100,000$ & 13.54 & & \\
\hline & More than $\$ 100,000$ & 21.40 & & \\
\hline \multirow[t]{6}{*}{ Bags } & $\begin{array}{l}\text { How often the consumer uses or } \\
\text { prefers to use canvas or reusable } \\
\text { bags (Likert scale 1-5): }\end{array}$ & & 2.7424 & 1.4046 \\
\hline & 1 & 26.64 & & \\
\hline & 2 & 18.78 & & \\
\hline & 3 & 24.02 & & \\
\hline & 4 & 14.85 & & \\
\hline & 5 & 15.72 & & \\
\hline \multirow[t]{6}{*}{$\begin{array}{l}\text { Purchase of } \\
\text { ecolabeled } \\
\text { products }\end{array}$} & $\begin{array}{l}\text { How often the consumer } \\
\text { purchases ecolabeled products } \\
\text { (Likert scale 1-5): }\end{array}$ & & 2.7293 & 1.2794 \\
\hline & 1 & 21.40 & & \\
\hline & 2 & 22.27 & & \\
\hline & 3 & 30.57 & & \\
\hline & 4 & 13.54 & & \\
\hline & 5 & 12.23 & & \\
\hline
\end{tabular}


Given this probability formulation and under the assumption that $W T P_{i}\left(z_{i}, u_{i}\right)=$ $z_{i}^{\prime} \beta+u_{i}$ and $u_{i} \sim N\left(0, \sigma^{2}\right)$, we have that the probability of the first of the three cases $\left(y_{i}^{1}=1\right.$ and $\left.y_{i}^{2}=0\right)$ is given by

$$
\begin{aligned}
\operatorname{Pr}(s, n) & =\operatorname{Pr}\left(t^{1} \leq W T P<t^{2}\right) \\
& =\operatorname{Pr}\left(t^{1} \leq z_{i}^{\prime} \beta+u_{i}<t^{2}\right) \\
& =\operatorname{Pr}\left(\frac{t^{1}-z_{i}^{\prime} \beta}{\sigma} \leq \frac{u_{i}}{\sigma}<\frac{t^{2}-z_{i}^{\prime} \beta}{\sigma}\right) \\
& =\Phi\left(\frac{t^{2}-z_{i}^{\prime} \beta}{\sigma}\right)-\Phi\left(\frac{t^{1}-z_{i}^{\prime} \beta}{\sigma}\right),
\end{aligned}
$$

where the last expression follows from $\operatorname{Pr}(a \leq X<b)=F(b)-F(a)$ and $t^{i}$ represents the alternative. Therefore, using symmetry of the normal distribution, we have

$$
\operatorname{Pr}(s, n)=\Phi\left(z_{i}^{\prime} \frac{\beta}{\sigma}-\frac{t^{1}}{\sigma}\right)-\Phi\left(z_{i}^{\prime} \frac{\beta}{\sigma}-\frac{t^{2}}{\sigma}\right)
$$

The other two probabilities can be derived by manipulating this first probability, which is derived from the following censored likelihood function:

$$
\begin{aligned}
& \sum_{i=1}^{N}\left\{d_{i}^{s n} \ln \left[\Phi\left(z_{i}^{\prime} \frac{\beta}{\sigma}-\frac{t^{1}}{\sigma}\right)-\Phi\left(z_{i}^{\prime} \frac{\beta}{\sigma}-\frac{t^{2}}{\sigma}\right)\right]+d_{i}^{s s} \ln \left[\Phi\left(z_{i}^{\prime} \frac{\beta}{\sigma}-\frac{t^{2}}{\sigma}\right)\right]\right. \\
& \left.+d_{i}^{n n} \ln \left[1-\Phi\left(z_{i}^{\prime} \frac{\beta}{\sigma}-\frac{t^{2}}{\sigma}\right)\right]\right\},
\end{aligned}
$$

where $d_{i}^{s n}, d_{i}^{s s}$, and $d_{i}^{n n}$ are indicator variables that take the value of one or zero depending on the relevant case for each individual-that is to say, a given individual contributes to the logarithm of the likelihood function in only one of its four parts.

Compared with a double-bounded CVM, the bound-and-a-half CVM reduces the potential for response bias on the follow-up bid (Cooper, Hanemann, and Signorello, 2002). There has been controversy with the double-bounded approach as there is evidence that responses to the first price may sometimes be inconsistent with the responses to the second (Cooper, Hanemann, and Signorello, 2002; DeShazo, 2002; Hanemann, 1991; McFadden and Leonard, 1993). The bound-and-a-half CVM allows a balance between efficiency and response bias, which is why it is employed with this survey.

The reference price, or the price of the plastic bottled milk, was $\$ 2.75$, and the different premium levels were added on top of this price for the glass-bottled milk. The WTP analysis was bounded at a maximum price of $\$ 4.00$ for milk in glass bottles, or a $\$ 1.25$ premium level, which was calculated using the Turnbull estimator. Premium levels were randomly assigned to consumers as they entered 
the grocery store. The specific premium levels for the first CVM question were $\$ 0.05, \$ 0.10, \$ 0.20, \$ 0.35$, and $\$ 0.50$.

The dependent variable was censored at a zero premium level in order to eliminate negative WTP estimates. A negative value would imply that the consumer preferred glass packaging at a lower price than the alternative, which might very well be the case. However, the cost to the seller of providing glass packaging is greater than that for either plastic or paperboard (Neill and Williams, 2015). We therefore assume that glass packaging is not available to the consumer at a lower price than plastic or paperboard. Additionally, we are only interested in estimating a mean WTP for those respondents that indicate a preference for glass packaging in the case that prices are the same for all options.

The interval regression analysis was conducted in SAS v. 9.3, using the LIFEREG procedure. LIFEREG was selected for numerous reasons. First, the parameter estimates are directly interpreted as changes in the marginal WTP. Second, it uses the maximum likelihood estimation method, through which the researcher is able to define the distribution. For ease of interpretation, the logistic distribution was used in the estimation. Finally, this procedure allows the researcher to censor the dependent variable, which is especially useful when attempting to estimate the effects of a bound-and-a-half CV question. An example of the CV portion of the survey is shown in Figure 1.

\section{Results}

\subsection{WTP Models}

Alternative methods exist for the estimation of WTP from the results of statistical analysis. WTP may be estimated for every individual in the sample or for "types" of individuals possessing certain characteristics of interest, or WTP may be evaluated at the average of the explanatory variables. For the purposes of this research, we are primarily interested in the average WTP of the entire population and the WTP of those respondents that indicated a willingness to purchase glass-bottled milk over alternative packaging when offered at the same price.

Table 2 illustrates how the varying levels of WTP were distributed. This table assists in understanding how the consumers reacted to the different premium levels. Only $18.78 \%$ of the consumers surveyed are not willing to pay any premium amount, whereas $62.01 \%$ are willing to pay both premium amounts that were presented to them. Approximately $12.66 \%$ are willing to pay the first premium presented to them but are not willing to pay twice that premium. At the same time, $6.11 \%$ of the consumers find the first premium to be too large but are still willing to pay some unknown premium less than the one they were presented. 
8. Do you believe it is solely a firm's responsibility to provide environmentally friendly products, in order to minimize negative impacts on the environment?

$$
\text { Yes No }
$$

9. On a scale of 1 to 5 with 1 being never and 5 being very often/always, how often do you purchase food products that are labeled such as organic, free range/cage free, Rainforest Alliance, Wild Caught, natural, or non-GMO?

$$
\begin{array}{lllll}
1 & 2 & 3 & 4 & 5
\end{array}
$$

10. On a scale of 1 to 5 with 1 being never and 5 being very often/always, how often do you currently use, or prefer to use, canvas and/or reusable bags when you purchase groceries?

$\begin{array}{lllll}1 & 2 & 3 & 4 & 5\end{array}$

11. Do you feel that it is your responsibility to seek out environmentally friendly products, in order to minimize negative impacts on the environment?

$$
\text { Yes No }
$$

12. Do you perceive a returnable glass bottle to be more environmentally friendly than a plastic bottle?

$$
\text { Yes No Unsure }
$$

13. If all were the same price and type of milk, which milk packaging would you choose?

$$
\text { Gable Top (Paper Board) Plastic Returnable Glass }
$$

14. Assume that you pay a deposit for the returnable glass bottle, and receive the deposit back when you return it to the store. Also assume that the milk in the glass bottle is locally produced. With the following prices, which milk packaging would you choose?

$$
\text { Plastic at } \$ 2.75 / \text { half gallon Returnable Glass at } \$ 2.80 \text { / half gallon }
$$

15. If you chose the Returnable Glass bottle in the previous question (question 14), which milk packaging would you choose with these new prices?

$$
\text { Plastic at } \$ 2.75 / \text { half gallon Returnable Glass at } \$ 2.85 \text { / half gallon }
$$

16. If you chose the plastic container in the question 14 , would you be willing to pay any premium for the glass bottle? Yes No, If, no why not?

Figure 1. Contingent Valuation Portion of the Survey

The results of the interval regression are presented in Table 3. The mean WTP estimated using the results from the regression was a 59.78 cent premium, or approximately $\$ 3.35$ for the returnable glass bottle as compared with $\$ 2.75$ for a plastic container. The lower and upper bounds of the WTP premium were 33.03 cents and 86.53 cents, respectively, or product prices of approximately $\$ 3.08$ and $\$ 3.62$, respectively.

The other statistically significant variables at the $1 \%$ level are Perception and Purchase of ecolabeled products. If consumers perceive the returnable glass bottle to be more environmentally friendly than plastic, they are willing to pay an additional 26.78 cents. The more often a consumer purchases ecolabeled products, the greater their likelihood of paying an additional 8 cents for each increase on the Likert scale. 
Table 2. Willingness-to-Pay Premium Distribution

\begin{tabular}{llccc}
\hline \hline Premium Level Combination & $\%$ Yes, Yes & $\%$ Yes, No & $\%$ No, Yes & $\%$ No, No \\
\hline \$2.80; \$2.85 & 19.72 & 3.45 & 0.00 & 9.30 \\
$\$ 2.85 ; \$ 2.95$ & 14.49 & 6.90 & 0.00 & 11.63 \\
$\$ 2.95 ; \$ 3.15$ & 28.73 & 55.17 & 21.43 & 34.88 \\
$\$ 3.10 ; \$ 3.45$ & 13.38 & 13.79 & 50.00 & 18.60 \\
$\$ 3.25 ; \$ 3.75$ & 22.54 & 20.69 & 28.57 & 25.58 \\
$\%$ of Total sample & 62.01 & 12.66 & 6.11 & 18.78 \\
\hline \hline
\end{tabular}

Table 3. Willingness-to-Pay for Milk Packaged in Returnable Glass Bottle, Regression

\begin{tabular}{lclc}
\hline \hline Parameter & Estimate & Standard Error & Pr > Chi-Square \\
\hline Intercept & $3.3838^{* * *}$ & 0.2089 & $<0.0001$ \\
Age & 0.0980 & 0.1621 & 0.5457 \\
Age squared & -0.0140 & 0.0339 & 0.6801 \\
Gender & -0.0744 & 0.0548 & 0.1748 \\
Household size & $-0.0757^{* * *}$ & 0.0229 & 0.001 \\
Education & 0.6226 & 0.4843 & 0.1986 \\
Household income & 0.0494 & 0.0348 & 0.1555 \\
Household income squared & -0.0001 & 0.0001 & 0.2352 \\
Income/education interaction & -0.7106 & 0.4849 & 0.1428 \\
Personal responsibility & -0.0675 & 0.0568 & 0.2348 \\
Perception & $0.2678^{* * *}$ & 0.0582 & $<0.0001$ \\
Local & 0.0315 & 0.0541 & 0.5604 \\
Bags & $0.0381^{*}$ & 0.021 & 0.0696 \\
Purchase of ecolabeled products & $0.0668^{* * *}$ & 0.0223 & 0.0028 \\
Scale & 0.3402 & 0.0178 & \\
Log likelihood & -202.555 & & \\
\hline \hline
\end{tabular}

Note: Asterisks $\left({ }^{*},{ }^{* *}\right.$, and $\left.{ }^{* * *}\right)$ indicate statistical significance at the $10 \%, 5 \%$, and $1 \%$ levels, respectively.

At the $10 \%$ level, the variable Bags is statistically significant. This shows that the more often consumers use canvas or reusable bags at the grocery store, the more they increase their WTP by approximately 3.8 cents. Also, as household size increases, a consumer's WTP decreases by 7.5 cents. None of the other demographic variables are statistically significant. In order to determine if the absence of consumer beliefs leads to bias, a model was run without the Perception variable (Table 4). Previous statistically significant variables have a higher level of significance statistically and economically.

For further comparison, a model was run with just an intercept. The intercept was significant at the $1 \%$ level and showed a base WTP of $\$ 3.31$, or a base premium of approximately 56 cents that surveyed consumers were willing to pay for milk in a glass bottle. The results of this model can be seen in the Table 5 . 
Table 4. Willingness-to-Pay for Milk Packaged in Returnable Glass Bottle, Regression without Perception Variable

\begin{tabular}{lclc}
\hline \hline Parameter & Estimate & Standard Error & Pr > Chi-Square \\
\hline Intercept & $3.503^{* * *}$ & 0.2271 & $<0.0001$ \\
Age & 0.1005 & 0.1781 & 0.5728 \\
Age squared & -0.0114 & 0.0376 & 0.762 \\
Gender & -0.0875 & 0.0611 & 0.152 \\
Household size & $-0.0956^{* * *}$ & 0.0247 & 0.0001 \\
Education & 0.4208 & 0.5267 & 0.4243 \\
Household income & 0.036 & 0.0378 & 0.3406 \\
Household income squared & -0.0001 & 0.0001 & 0.4552 \\
Income/education interaction & -0.5249 & 0.5263 & 0.3185 \\
Personal responsibility & -0.0697 & 0.0631 & 0.2694 \\
Local & 0.0183 & 0.0612 & 0.7643 \\
Bags & $0.0624^{* * *}$ & 0.0227 & 0.0061 \\
Purchase of ecolabeled products & $0.0819^{* * *}$ & 0.025 & 0.001 \\
Scale & 0.2087 & 0.0127 & \\
Log likelihood & -219.68 & & \\
\hline \hline
\end{tabular}

Table 5. Willingness-to-Pay for Milk Packaged in Returnable Glass Bottle, Regression with Intercept Only

\begin{tabular}{llll}
\hline \hline Parameter & Estimate & Standard Error & $\operatorname{Pr}>$ Chi-Square \\
\hline Intercept & $3.3117^{* * *}$ & 0.0338 & $<0.0001$ \\
Log likelihood & -248.047 & & \\
\hline \hline
\end{tabular}

\subsection{Logit Models}

To analyze which consumers have a preference for the glass-bottled milk, a traditional logit model was estimated. The model components are similar to the WTP model with the change of the dependent variable to Stated, which is a binary variable of whether the consumer prefers the glass bottle. The purpose of using Stated as the dependent variable is to determine what the preferred milk packaging of the consumers is in regard to alternative milk packaging. Specifically, the regression is focused on consumers' stated preference toward a returnable glass bottle. The results of this regression are shown in Table 6.

This type of regression provides a stated preference analysis of the consumers in this geographic area in regard to a perceived environmental attribute. Stated preference is critical for comparison to the WTP regression because if a consumer prefers glass, ceteris paribus, then he or she is more likely to accept a price premium to purchase glass.

The results of the logit model indicate that five variables are statistically significant. The variable with the largest impact on a consumer's stated preference 
Table 6. Stated Preference Regression for Milk Packaged in Returnable Glass Bottle

\begin{tabular}{lcccc}
\hline \hline Parameter & Estimate & Odds Ratio & Standard Error & Pr $>$ Chi-Square \\
\hline Intercept & 0.9052 & - & 1.4532 & 0.5333 \\
Age & -1.053 & 0.349 & 1.1253 & 0.3495 \\
Age squared & 0.1957 & 1.216 & 0.2379 & 0.4107 \\
Gender & -0.155 & 0.857 & 0.3883 & 0.6908 \\
Household size & -0.147 & 0.864 & 0.1592 & 0.3574 \\
Education & 5.0192 & 151.29 & 3.5559 & 0.1581 \\
Household income & 0.3174 & 1.374 & 0.2556 & 0.2144 \\
Household income squared & $-7 \mathrm{E}-04$ & 0.999 & 0.0007 & 0.3244 \\
Incomeleducation interaction & -4.933 & 0.007 & 3.5541 & 0.1652 \\
Personal responsibility & -0.087 & 0.917 & 0.3969 & 0.8268 \\
Perception & $1.3957^{* * *}$ & 4.038 & 0.223 & $<0.0001$ \\
Local & -0.415 & 0.66 & 0.3843 & 0.28 \\
Bags & $0.4065^{* * *}$ & 1.502 & 0.1516 & 0.0073 \\
Purchase of ecolabeled products & $0.3421^{* *}$ & 1.408 & 0.1583 & 0.0307 \\
Log likelihood & -141.8 & & & \\
\hline \hline
\end{tabular}

Note: Asterisks $\left(*, * *\right.$, and $\left.{ }^{* * *}\right)$ indicate statistical significance at the $10 \%, 5 \%$, and $1 \%$ levels, respectively.

for milk packaged in a returnable glass bottle is Perception. The results reveal that a person is 4.038 times more likely to have a stated preference for the returnable glass bottle if he or she perceives it to be more environmentally friendly than plastic. It was hypothesized that someone who perceived the returnable glass bottle to be more environmentally friendly than plastic would have an increased likelihood to prefer the glass alternative.

Furthermore, the more often a consumer shops with canvas or reusable bags, the more likely (1.502 times) he or she is to have stated that he or she has a preference for the returnable glass bottle. Similarly, the more often a consumer purchases ecolabeled products (i.e., for each increase on the Likert scale), the more likely (1.408 times) the consumer is to have stated that he or she has a preference for the returnable glass alternative. Also, even though the education variable is not statistically significant, it is economically significant in that for each increase in education, a consumer is 151.29 times more likely to prefer the returnable glass bottle.

Given that the primary goal of this research is to determine whether consumers are willing to pay for a perceived environmental attribute, it is important to determine which variables affect a consumer's perception of the returnable glass bottle. Table 7 shows the results of a traditional logit model with the dependent variable as Perception. In this case, the variables on the right-hand side of the model are the same as before, except that the Perception variable is removed and used as the dependent variable. However, any variables that result in significance demonstrate a pathway to explaining the WTP results. 
Table 7. Consumer Environmental Perception for Milk Packaged in Returnable Glass Bottle

\begin{tabular}{lcccc}
\hline \hline Parameter & Estimate & Odds Ratio & Standard Error & Pr > Chi-Square \\
\hline Intercept & -0.1384 & \multicolumn{1}{c}{-1.0120} & 0.9120 \\
Age & -0.3420 & 0.710 & 0.1179 & 0.7314 \\
Age squared & 0.1046 & 1.110 & 0.2399 & 0.6243 \\
Gender & -0.00018 & 1.000 & 0.0000 & 0.9996 \\
Household size & -0.1795 & 0.836 & 1.7356 & 0.1877 \\
Education & -3.1469 & 0.043 & 1.1832 & 0.2767 \\
Household income & -0.2355 & 0.790 & 1.2923 & 0.2556 \\
Household income squared & 0.000586 & 1.001 & 1.2188 & 0.2696 \\
Income/education interaction & 3.1952 & 24.415 & 1.2148 & 0.2704 \\
Personal responsibility & -0.1748 & 0.840 & 0.2615 & 0.6091 \\
Local & -0.1478 & 0.863 & 0.2018 & 0.6532 \\
Bags & $0.4613^{* * *}$ & 1.586 & 11.8502 & 0.0006 \\
Purchase of ecolabeled products & 0.0142 & 1.014 & 0.0113 & 0.9155 \\
Log likelihood & -134.715 & & & \\
\hline \hline
\end{tabular}

Note: Asterisks $\left({ }^{*},{ }^{* *}\right.$, and $\left.{ }^{* * *}\right)$ indicate statistical significance at the $10 \%, 5 \%$, and $1 \%$ levels, respectively.

After running the traditional logit, it was found that Bags was the only variable statistically significant at the $1 \%$ level in determining whether a consumer perceives the returnable glass bottle to be more environmentally friendly than plastic. Economically, this result means that the more often a consumer uses canvas or reusable bags, the more likely (1.586 times) he or she is to perceive the returnable glass bottle to be more environmentally friendly than plastic. Although this result does not directly explain the variation in perception, it does show that the perception of glass being environmentally friendly is why the consumer prefers glass.

\section{Discussion}

The most significant finding from this study is that people who perceive the returnable glass bottle to be more environmentally friendly than plastic are willing to pay an extra 26.78 cents. At the same time, approximately $72.5 \%$ of the survey respondents perceive the glass bottle to be environmentally friendly. If the Perception variable is taken out of the regression, the same set of variables is still significant but has a greater statistical and economic impact indicating bias of certain parameters as a result of disregarding a consumer's belief about the product.

The more often a consumer uses, or prefers to use, canvas or reusable bags when shopping for groceries, the more likely (i.e., $\sim 50 \%$ more likely at each level on the Likert scale) the consumer is to have a stated preference for the returnable glass bottle. Moreover, the more often a consumer purchases food products that 
are considered to be ecolabeled, the more likely ( $\sim 40 \%)$ the consumer is to have a stated preference for the returnable glass bottle.

These results can be extrapolated to estimate the WTP for specific consumer segments. The mean WTP within the study is for the entire sample. For those that have a higher likelihood of preferring the returnable glass, the corresponding WTP is estimated to be between 73 and 92 cents. However, the mean WTP is reflective of the price premium that dairies in other parts of the United States (i.e., the Danzeisen Dairy in Phoenix, Arizona) are charging for their glassbottled milk products (Merrill, 2015). Dairies can use the information from the various regressions to identify price points that both appeal to targeted consumers and offset the cost of packaging the milk in the returnable glass bottle.

It is important to note that there is the issue of hypothetical bias inherent in CVM because no money is transacted. To account for this, an ex post calibration is used by reducing the WTP amount by a factor of 2 . This would reduce the overall WTP to 13.39 cents, and the WTP for those with a higher likelihood of preferring the returnable glass to the range of 36.5 to 46 cents.

\section{Conclusions}

Overall, it was found that consumers, on average, are willing to pay a premium for milk packaged in a returnable glass bottle. This is significant because there is no identifying label suggesting that the bottle is environmentally friendly. The idea that consumers do perceive returnable glass packaging to be more environmentally friendly than plastic shows that there is precedence for more research into these types of products. If there are other products similar to the returnable glass bottle, whether they truly have a lower environmental impact, then consumers could be indirectly creating a market for these products.

The multiple regressions used within this study reveal a pathway that contributes to the understanding of the information. In the perception regression, it was found that the more often a consumer uses canvas or reusable bags, the higher the likelihood that the consumer perceives the glass bottle to be more environmentally friendly. From this regression, it was seen that a consumer's stated preference for the returnable glass alternative was not only based on the Bags and Perception variables, but was also influenced by Household size and Purchase of ecolabeled products. Finally, both the perception of environmental friendliness and WTP for glass packaging are explained by the same pattern of statistically significant explanatory variables.

From the results of the analysis, the types of consumers that have a stated preference for milk packaged in a returnable glass bottle are people that prefer to buy ecolabeled food products and/or use canvas/reusable bags when they shop for groceries. It is also important to note that the consumers that perceive 
the glass bottle to be environmentally friendly are those that willing to pay the highest premium. By introducing glass-bottled milk, dairies may take advantage of a unique market segment through product differentiation.

This research has successfully demonstrated that some consumers are willing to pay for an environmental attribute that they believe a particular product possesses. A majority of the consumers surveyed perceived a returnable glass milk bottle to be more environmentally friendly than plastic, which means that there is precedence for future research in this area to determine what other products consumers perceive to possess environmental attributes.

Future research should focus on determining potential consumer return rates of the glass bottle to the store in order to determine if the calculated WTP return rate is in line with the likelihood of actual consumer return rates. If these two variables do not align, then the returnable glass bottle would not be the optimal social choice. Other research should focus on expanding the idea of the perceived environmental attribute to other types of products and geographic locations to determine if the results of this study hold true on a broader scale. The primary limitation to the study is the limited sample from only one source. Although the sample did represent the general population within the study area, there is concern that not all possible consumer segments were represented. Therefore, the generalizability of the results is weak, and further investigation of these results in samples from other populations could be pursued. In general, there are opportunities to enhance consumer-based studies to include beliefs/perceptions, which will reduce bias in WTP estimates. We have shown that the exclusion of a consumer's perceptions can have a significant impact on the other parameters in the model, which supports the implications put forth by Lusk, Schroeder, and Tonsor (2014).

\section{References}

Bajari, P., and C.L. Benkard. "Demand Estimation with Heterogeneous Consumers and Unobserved Product Characteristics: A Hedonic Approach.” National Bureau of Economic Research (NBER) technical working paper 272, Cambridge, MA: NBER, 2001.

Cooper, J.C., M. Hanemann, and G. Signorello. "One-and-One-Half-Bound Dichotomous Choice Contingent Valuation." Review of Economics and Statistics 84,4(2002):74250.

DeShazo, J.R. "Designing Transactions without Framing Effects in Iterative Question Formats." Journal of Environmental Economics and Management 43,3(2002):360-85.

Gallardo, R.K., and Q. Wang. "Willingness to Pay for Pesticides' Environmental Features and Social Desirability Bias: The Case of Apple and Pear Growers.” Journal of Agricultural and Resource Economics 38,1(2013):124-39.

Ghenai, C. "Life Cycle Assessment of Packaging Materials for Milk and Dairy Products." International Journal of Thermal \& Environmental Engineering 4,2(2012): 117-28. 
Greene, C. Organic Market Overview. Washington, DC: U.S. Department of Agriculture, Economic Research Service. Internet site: http://www.ers.usda.gov/topics/naturalresources-environment/organic-agriculture/organic-market-overview.aspx (Accessed August 1, 2016).

Hanemann, W.M. "Comments." A Contingent Valuation Survey of the Kakadu Conservation Zone. D. Imber, G. Stevenson, and L. Wilks. Canberra, Australian Capital Territory, Australia: Australian Government Publishing Service, Resource Assessment Commission research paper 3, 1991, pp. 187-92.

Hollywood, L., L. Wells, G. Armstrong, and H. Farley. "Thinking Outside the Carton: Attitudes towards Milk Packaging.” British Food Journal 115,6(2013):899-912.

Johannson-Stenman, O., and P. Martinsson. "Honestly, Why Are You Driving a BMW?" Journal of Economic Behavior \& Organization 60,2(2006):129-46.

Lopez-Feldman, A. "Introduction to Contingent Valuation using Stata." Munich Personal RePEc Archive (MPRA) paper 41018, Munich, Germany: MPRA, 2012.

Loureiro, M.L., and S. Hine. "Discovering Niche Markets: A Comparison of Consumer Willingness to Pay for Local (Colorado Grown), Organic, and GMO-Free Products.” Journal of Agricultural and Applied Economics 34,3(2002):477-87.

Loureiro, M.L., J.J. McCluskey, and R.C. Mittelhammer. "Assessing Consumer Preferences for Organic, Eco-labeled, and Regular Apples." Journal of Agricultural and Resource Economics 26,2(2001):404-16.

Lusk, J.L., and F.B. Norwood. "Bridging the Gap between Laboratory Experiments and Naturally Occurring Markets: An Inferred Valuation Method." Journal of Environmental Economics and Management 58,2(2009a):236-50.

—. "An Inferred Valuation Method." Land Economics 85,3(2009b):500-514.

Lusk, J.L., T.C. Schroeder, and G.T. Tonsor. "Distinguishing Beliefs from Preferences in Food Choice." European Review of Agricultural Economics 41,4(2014):627-55.

McFadden, D.L., and G.K. Leonard. "Issues in Contingent Valuation of Environmental Goods: Methodologies for Data Collection and Analysis." Contingent Valuation: A Critical Assessment. J.A. Hausman, ed. Amsterdam, The Netherlands: North-Holland, 1993, pp. 165-216.

Merrill, L. "Phoenix Dairy Goes Retro with Glass Bottles." Arizona Republic, April 20, 2015. Internet site: http://www.azcentral.com/story/money/business/2015/04/18/ phoenix-dairy-goes-retro-glass-bottles/25975067/ (Accessed July 20, 2016).

Neill, C.L., and R.B. Williams. "An Economic Valuation on the External Cost of Alternative Milk Packaging." Journal of Food Distribution Research 46,3(2015):68-80.

Norwood, F.B., and J.L. Lusk. "Social Desirability Bias in Real, Hypothetical, and Inferred Valuation Experiments.” American Journal of Agricultural Economics 93,2(2011):52834.

Thistlethwaite, R. Straus Family Creamery \& Dairy: Marshall, California. Innovative Business Models and Case Studies Series no. 6, Santa Cruz: Center for Agroecology and Sustainable Food Systems, University of California Santa Cruz, 2010. Internet site: http://casfs.ucsc.edu/documents/business-models/CaseStudy_no6_Straus.pdf (Accessed May 4, 2016).

Toro-González, D., R.K. Gallardo, J. Yan, and J.J. McCluskey. "Quality Differentiation with Flavors: Demand Estimation of Unobserved Attributes.” Journal of Agricultural \& Food Industrial Organization 11,1(2013):101-11.

Transparency Market Research. Glass Packaging Market for Food \& Beverages, Pharmaceuticals, Beer and Other Alcoholic Beverages - Global Industry Analysis, Size, 
Share, Growth, Trends and Forecast 2014-2020. Albany, NY: Transparency Market Research, 2014.

U.S. Census Bureau. “QuickFacts: Lubbock County, Texas.” Internet site: http://www. census.gov/quickfacts/table/PST045215/48303 (Accessed May 10, 2014).

Zaleski, W.R. "Plastic Bottle." US Patent 3,086,671, filed August 17, 1962, and issued April 23, 1963. 